\begin{tabular}{rr} 
çağdaş & Yaratıci Drama Dergisi 2017, 12(2), 1-16 \\
drama & www.yader.org \\
\hline
\end{tabular}

\title{
Yaşayan Müze Kavramı Üzerine Bir İnceleme
}

\author{
Kadriye Tezcan Akmehmet ${ }^{1}$
}

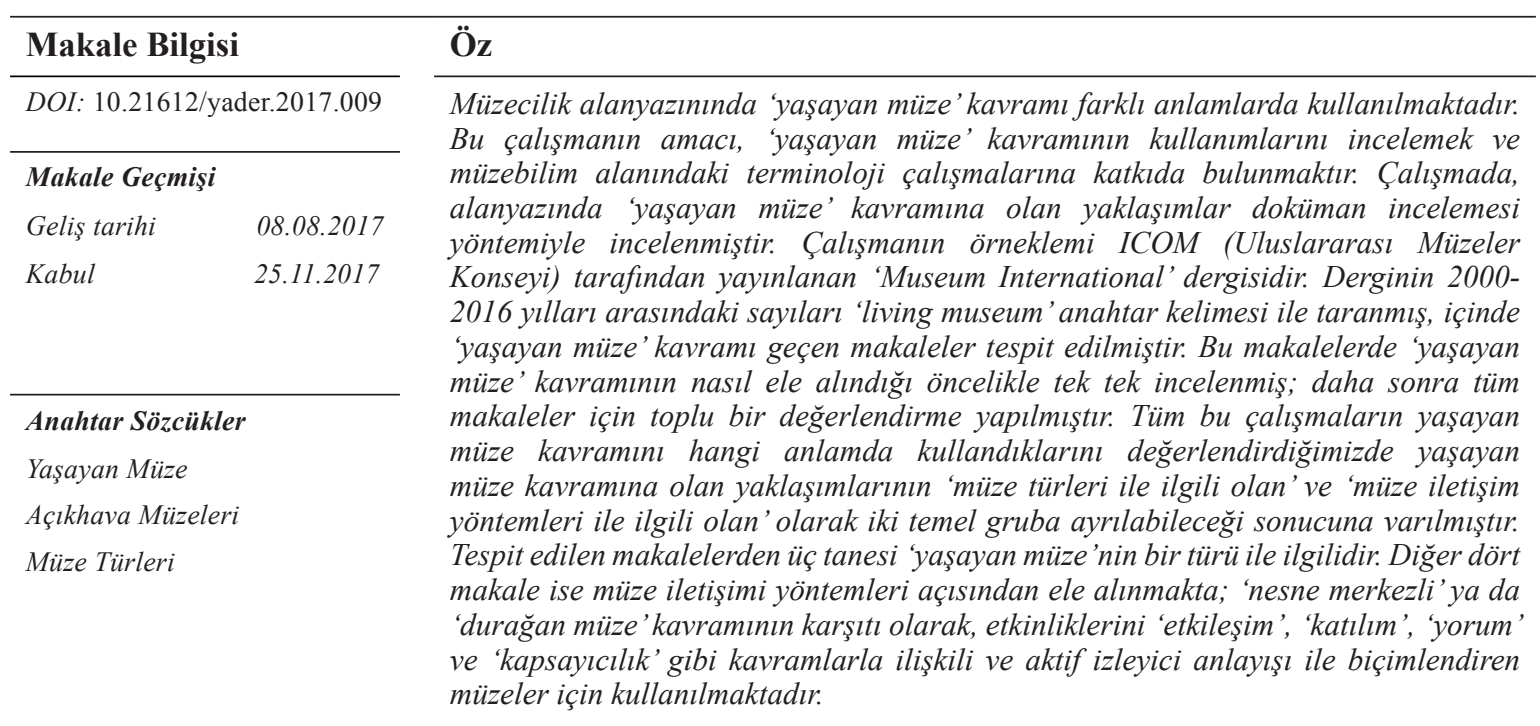

\section{An Analysis of the Concept of Living Museum}

\begin{tabular}{lr}
\hline Article Info \\
\hline DOI: $10.21612 /$ yader.2017.009 \\
\hline & \\
\hline Article History & \\
Received & 08.08 .2017 \\
Accepted & 25.11 .2017
\end{tabular}

Keywords

Living Museum

Open-Air Museum

Types of Museums

\begin{abstract}
The concept of 'living museum' has been used in different meanings in the field of museology. The aim of this study is to examine the use of the concept of 'living museum' and to contribute to current museological terminology. In the study, approaches to the concept of 'living museum' were examined by document analysis method in the literatur. The sample of the study is 'Museum International' Journal that pulished by ICOM (International Council of Museums). The articles that refer to the concept of 'living museum' have been determined in the issues of the journal between 2000-2016. In these articles, the way in which the concept of 'living museum' is addressed is examined firstly for each article and then a general view was put forward. The study suggests that the approaches to the concept of 'living museum' could be divided into two basic groups as 'related to museum types' and 'related to museum communication methods'. Three of the identified articles are related to a type of 'living museum'. In the other four studies, the 'living museum' is used as opposite to the concept of 'object-centered' or 'stationary museum and it is addressed for museums organizing their activities on the basis of active audience approach related to museum communication methods.
\end{abstract}

1 Doç. Dr., Yıldız Teknik Üniversitesi Sanat ve Tasarım Fakültesi Müzecilik Yüksek Lisans Programı Yürütücüsü, E-posta: kadriyetezcan@gmail.com 


\section{Giriş}

Günümüzde müzelerin temel sorumluluğu 'nesne' merkezli yaklaşımdan 'insan ve toplum' merkezli yaklaşıma yönelmiştir. Müzecilikte artık müzelerin kamusal boyutu ve toplumun somut ve somut olmayan kültürel mirasa erişimi ile ilişkili konular önem kazanmaktadır. Bu anlayış müzenin nesne merkezli sergilerin yanında etkinlikleriyle varolmasını ve bir hazine/depodan çok atölye gibi işlemesini; hatta çekici ve eğitsel deneyimler ve yorumlar sunmasını gerektirmektedir. 'Yaşayan müze' bu anlayış içinde müzecilikte en önemli kavramlardan biri olarak önem kazanmaktadır.

Alanla ilgili çalışmalarda 'Yaşayan müze' kavramının farklı anlamlarda kullanıldığ görülmektedir. 'Müze' kavramı gibi müzecilik terminolojisi de oldukça karışıktır. Avrupa müzeciliğinin önemli aktörlerinden Kenneth Hudson, "Museum Refuses to Stand Still/Müzeler Yerinde Saymay1 Reddediyor" adlı makalesinde (1998, s.45), katıldığı bir konferansta bir konuşmacinın şunu aktardığını ifade eder: 'Küçük bir çocukken bir müze gördüğüm zaman onun bir müze olduğunu anlıyordum; ancak şimdi her zaman emin olamıyorum.' Ardından ICOM'un Hollanda'da 5 Eylül 1986 'da toplanan Genel Kurulunda benimsenen ve Norveç'te 7 Temmuz 1995'te toplanan 18. ICOM Genel Kurulunda yeniden düzenlenerek kabul edilen bildirgenin 2. maddesi de (1.a şıkkında) müzenin sınırlarının tanımlamasının da müze uygulamalarının kavranmasına yardımcı olmadığını ekler:

- Toplum ve çevresi ile ilgili malzemeyi sunan, koruyan ve toplayan müze karekterindeki sit alanları ve tarihi anıtlar, doğal, arkeolojik ve etnografik anıtlar ve sitler,

- Yaşayan bitki ve hayvan türleri ile ilgili koleksiyonları bünyesinde barındıran botanik ve zooloji bahçeleri, akvaryumlar,

- Bilim merkezleri ve planeteryumlar,

- Arşivler ve kütüphaneler tarafından sürekli olarak tutulan sergilemeler, konservasyon enstitüleri,

- Doğal rezerv alanları,

- Bir sonraki maddedeki tanımlara uygun müzelerden sorumlu uluslararası, ulusal, bölgesel ya da yerel müze organizasyonları, bakanlıklar, bölümler, müdürlükler,

- Müzeler ve müzebilim ile ilgili araştırma, eğitim, öğretim, belgeleme ve diğer etkinlikleri yürüten, kar amacı gütmeyen kurum ve kuruluşlar, benzeri yapılanmalar.

Birleşmiş Milletler Eğitim, Bilim ve Kültür Teşkilatı'nın(UNESCO), 1972 yılında hazırladığ Kültürel ve Doğal Mirası Koruma Sözleşmesi’yle, yaşayan kültürlerin korunması yaklaşımının benimsenmesi de müzecilik çalışmalarını etkilemiş; klasik müzecilik anlayışında olduğu gibi, nesneleri bir binanın sınırları içindeki kapalı mekânlarda sergilemek yerine farklı sergileme biçimleri müze kapsamında kabul edilmiştir. Hudson $(1998$, s.6) o dönem için, bir hayvanat bahçesi ya da bilim merkezinin müze sayılabilmesinin ve bir bitki, balık ya da hayvana 'nesne' demenin pek çok insan için kabul edilebilir bir fikir olmadığını ifade etmektedir. Bu tanımdan da anlaşılacağı gibi yaşayan bitki ve hayvan türlerini barındıran ve topluma sunan botanik ve zooloji bahçeleri ile arkeolojik hatta doğal sit alanları müze olarak kabul edilmektedir.

UNESCO tarafından (2003) miras kelimesinin kapsamının genişletilmesi de müze tanımını etkilemiştir. Nesli tükenmekte olan diller, sözlü miras, geleneksel müzik ve performans biçimleri, gümrük, törenler, folklor, topluluklar ile grupların somut olmayan ve yaşayan mirasları da kültürel miras tanımına dahil edilmiş; ardından müze tanımının kapsamı da Seul'de düzenlenen 21. ICOM 
Genel Kurulu'nda şu şekilde genişletilmiştir: “Müze, toplumun ve gelişiminin hizmetinde olan, halka açık, insana ve yaşadı̆̆ çevreye dair tanıklık eden somut ve somut olmayan malzemeler üzerine araştırma yapan, toplayan, koruyan, bilgiyi paylaşan ve inceleme, eğitim ve zevk alma amactyla sergileyen, kâr amacı gütmeyen, sürekliliği olan bir kurumdur.” 2003’te UNESCO Somut Olmayan Kültürel Mirasın Korunması Sözleşmesinin imzalanmasından bu yana, somut olmayan mirasın giderek önem kazanmasıyla müzeler, koleksiyonlarında ve sergilerinde, yaşayan kültürlerini temsil ettikleri topluluklarla çalışmanın ve yorumlayıcı çalışmaların öneminin farkına varmışlardır. $\mathrm{Bu}$ nedenle özellikle 2003 yılı sonrasında 'yaşayan müze'kavramı da giderek önem kazanmıştır.

\section{Yaşayan Müzenin Anlamı ve Amacı}

Yaşayan müzenin ne olduğu konusunda çeşitli yayınlarda farklı kullanımlar görülmektedir. Genellikle halk mirası veya yöresel kültürel miras ile ilişkilendirilen yaşayan müzeler, toplumsal tarihi ve geleneksel yaşam biçimlerini temsil etmeyi amaçlamaktadırlar. Uluslararası Müzeler Konseyi (2008) yaşayan müzeyi açık hava müzesi ile eş anlamlı kullanmış; koleksiyonlarını kapılarının dışında/dış mekânda sergileyen ayrı bir müze türü olarak bu tanımla ilişkili müzeleri; açık hava müzeleri, binalar müzesi, çiftlik müzeleri, yaşayan tarih müzesi ve halk müzeleri olarak örneklendirimiştir (Sukmataji, 2010, s.11). Letsebe (2012) ise müze ortamını anlamlandırmada en etkili yolun yaşayan müzeler aracılığıyla olduğunu belirtmekte, sanayi (örneğin madencilik) müzeleri, tarihi savaş canlandırmaları, canlı aktörlerin (bazen hayvanlarla) gerçekleştirdiği el sanatları sergileri gibi birçok bağlamda ve perspektifte yaşayan müzelerin görüldüğünü ifade etmektedir.

ICOM'a bağlı olarak çalışan Avrupa Açık Hava Müzeleri açık hava müzelerini şöyle tanımlar: 'yapısal ve işlevsel varlıklar olarak yerleşim şekillerini, konutları, ekonomiyi ve teknolojiyi gösteren çeşitli yapıların/kuruluşların açık havadaki bilimsel koleksiyonları' (AEOM, 2017a). AEOM (2017b)'e göre günümüzde açık hava müzeleri çok çeşitlidir. Her müze farklıdır, yaşam biçimi, gelenekler, yapı kültürü ve belirli bir bölgenin veya ülkenin tarihinin anahtarıdır. Açık hava müzeleri aynı zamanda benzerdir. Bilgilendirme ve sunma, üç boyutlu ve birebir ölçeğe göre sunma, ve birçok ziyaretçiye ve farklı hedef gruba ulaşma konusunda güçlü bir yeteneğe sahiptir. Açık hava müzelerinin çoğu yeri değiştirilmiş/taşınmış bina ve yapılardan oluşur; ancak bazı müzeler yapıları orijinal konumunda da değerlendirebilmektedir.

Yaşayan müzenin ne anlama geldiği konusunda farklı çalışmalarda farklı sınıflandırmalar yapılmaktadır. Chinatown'un geleneksel Çin kültürünü sergileyerek bir yaşayan müze işlevi gören Kültürel Temsiliyet ve Müzeler: Şikago Çin Mahallesinde Etnik Kimliğin Oluşturulması (Cultural Representations and Museums: The Construction of Ethnic Identity in Chicago's Chinatown) adl1 makalesinde Ko (2011) yaşayan müzenin iki farklı kurum için kullanıldığını belirtmektedir: Botanik bahçeleri ve yaşayan tarih müzeleri. Birmingham ve National Mall'daki botanik bahçelerini örnek vererek yaşayan bitki koleksiyonu olması nedeni ile yaşayan müze olarak değerlendirmektedir. İkinci tip olarak da yaşayan müzenin ikinci türü, sahnelenen performansları içeren tarihi yeniden yaplandırmalarla bağlantılıdır. Yaşayan müzeler, 'açık hava müzeleri' ve 'yaşayan tarih müzeleri”' ile örtüşen özelliklere sahiptir. Scott Magelssen yaşayan tarih müzelerini 'tarihi sergileri canlı kostümlü performansla birleştiren kültür kurumları’ olarak tanımlamaktadır. Bu terimin, eğitsel amaçlarla 'yeniden yapılandırılmış veya restore edilmiş bölgelerde kostümlü bir şekilde yorumlama yapmak ve tarihi tasvir etmek' için kullanıldığından bahsetmektedir. Çalışmasında, yaşayan müze ile özgün yapılara ya da tarihsel yeniden yapılandırmalara, yaşam biçiminin yeniden yaratılmasına ve 
sahnelenen performanslara atıfta bulunmakta; Chicago'nun Çin Mahallesini, yaşayan bir müzenin özelliklerine sahip olduğu için bir yaşayan müze olarak görmektedir. Tipik bir açık hava müzesi gibi ziyaretçilerinin farklı bir etnik çevreye girmeleri ve günlük hayatı gösteren otantik kültürel bir deneyim edinmeleri; ziyaretçilerin bölgenin gerçek sakinleri ile etkileşim kurarak değişen dinamikleri ve firsatları deneyimlemelerinin yanı sıra etnik lokantalarda yemek yemeleri ve diğer kültürel olayları deneyimlemeleri nedeniyle bu yaşayan müzenin, açık hava müzelerine benzer işlevlere sahip olduğunu söyler (Ko, 2011, s.214).

Galangau-Quérat ve Girault (2012), geleneksel değerleri ifade etmeyi amaçlayan yaşayan müzelerin kurulmasının, 'somut ve somut olmayan kültürel mirasın envanteri ve korunması ve geleneksel nesnelerin sergilenmesinin belirli bir yolu olduğu ve bu müzelerin çeşitli kültürel eylemler yürüttügü̈' tespitinde bulunmaktadır. Dürrschmidt (2012) yaşayan müzeler kuran kırsal toplumların ana hedefinin, kültürel inançları ve geleneksel becerilerini yaşatmak olduğunu; bir yaşayan müzenin sürdürülebilirliğini sağlamanın yolunun, ziyaretçilere geleneksel kültürün bir parçası olabilecekleri interaktif programlar sunmak olduğunu belirtmektedir. Namibya Yaşayan Kültür Vakfı'nın kültürel kimliğin kaybolma sürecinin Namibya'da desteklenen 'yaşayan müzeler' kavramıyla tersine çevrilebileceği varsayımını sunmakta; yaşayan müzenin, her şeyden önce, bir topluluğun çocuklarının kültürel geçmişlerini anlamaları için geleneksel bir okul ve geleneksel bilginin dağıtılabileceği bir yer olarak görüldüğ̈̈nü ve burada kültürel belleğin yeniden üretilebileceğini ifade etmektedir. Açık hava müzelerinde dönemin durağan ve nesne merkezli müzecilik anlayışına göre düzenlenmiş kapalı mekân müzelerinden farklı olarak, farklı müze deneyimlerinin yaşanabileceğı ve paylașılabileceği atmosferler yaratılmıştır.

Wilks ve Kelly’e göre (2008, s.129) geçmişte belli bir dönemin tarihinin durdurulmuş olduğu müzelere 'yaşayan' kelimesinin eklemlenmesi, ironik olarak görülmektedir. Yaşayan müzelerin, tarihi, geçmiş çağın dondurulmuş mükemmel fotoğrafı olarak sunduğunu ve miras deneyimi sağlayarak ziyaretçinin duygularıyla bireysel düzeyde etkileşime girmesine imkân sağladığını; hem kendi duygularını keşfettiğini, hem de tarihsel bir deneyim kazandıklarını belirtmektedirler. 'Nesne' mirasından 'özne' mirasına hareket etmeyi sağlayan deneyimler, hem temsil edilen hem de yorumlayan halkın kültürel ilgilerin merkezinde görülmesi, yaşayan müze fikrinin ayrılmaz bir parçasıdır (Wilks ve Kelly, 2008, s.129). Hooper-Greenhill'in aktif katılım olarak adlandırdığ1 gösterimler, canlı yorumlamalar ve atölye çalışmaları ile sağlanacak kişilerarası iletişim yöntemleri (1994), geleneksel sanatlar ya da endüstriyel üretimler gibi somut olmayan etkinlikler yaşayan müzeler için mutlaka gereklidir. Bu tür müzelerde, ziyaretçilerin pasif ziyaretçiler olmaları yerine ve serginin bir parçası haline gelmeleri için firsat tanınır (Aktaran Wilks ve Kelly, 2008, s.132). Wilk ve Kelly’e göre yaşayan müzelerin başarısı ziyaretçilerin somut olmayan miras etkinlikleri/ folklor ile etkileşime girmesini sağlayacak veya kendi hikayesini anlatacak karakterleri kullanmasıdır.

\section{Yaşayan Müzelerin Gelişimi ve Türleri}

Yaşayan müzelerin ilk örnekleri olarak açık hava müzeleri kabul edilmektedir. Bu müzelerin pek çogunun kurulus, amaçları, koleksiyonları ve sergi mekânı tasarımları birbirine oldukça benzerdir. Açık hava müzeleri aynı çağda sayıları gittikçe artan ulusal sanat ve tarih müzelerinde oldugu gibi yüksek sanat eserlerinin gösterildiği bir mekân olarak tasarlanmamıştır. Açık hava müzeleri Burke'nin değerlendirmesiyle (1996) resmi tarih yerine, halkların tarihinin yazılmaya bașlanması ile halk hareketinin bir uzantısı; resmi bir tarihi dayatan otoriter kurumlara bir başkaldırı; bir taraftan da 
Endüstri Devriminin geleneksel kırsal yaşam tarzları üzerinde algılanan tehdidine yanıt olarak kabul edilmektedir (Demir, 2013, s.152). Bir başka görüşe göre de bu tür faaliyetlerle insanlar arasında bir akrabalık duygusu olușturmak ve kuşaklararası iletiş̧imi sagłamak amaçlanmıştır (Rentzhog 2007). Açık hava müzelerinin doğuşuna, oluşum sürecine ilişkin fikrî temeller Avrupa'nın uluslaşma hareketi ile de ilişkilendirilmektedir. Açık hava müzelerini doğuran bir başka etken de turizmdir (Demir, 2013, s.151). Açık hava müzeleri ülkelere göre faklı anlamlar da taşımayabilmektedirler. Demir'in de (2013, s. 149) vurguladığ1 gibi, özellikle Kuzey Avrupa ülkeleri için endüstrileşmenin atıl kıldığ1 yaşantıyı çagrış̧ıırırken, Japonya için kültür emperyalizminin yok ettiğ geleneksel değerler olarak algilanabilir.

İsveç Stockholm'de Skansen tepesinde İsveç kültürel mirasını koruma temel fikriyle 1891 yılında açılan Skansen Açık Hava Müzesi, ilk açık hava müzesidir. Kurucusu Hazelius'un amaçlarının 'kendini tanı' sloganı ile yaşayan bir müze kurmak olduğunu ifade etmektedir (Kron, 2012, s.217). Hazelius'un 1873 'te kurduğu Nordiska Müzesi ile İskandinav dilinin konuşulduğu kırsal yaşam, mizansenler ve nesnelerle tanıtılmış; sıradan insanlar tarafından kullanılan günlük yaşam nesneleri toplanmaya başlanmış ve bu nesnelerle Skansen Müzesi Nordiska Müzesi’nin bir parçası olarak kurulmuş, sıradan insanların, köylülerin, kasabalıların, fakir ve evsizlerin tarihi kucaklanmıştır (Rentzog 2007). Bugün, değişik mesleklerin ve geleneklerin sergilendiği ülkenin dört bir yanından getirilmiş çiftlikler, atölyeler, ahırlar vardır. Burada ziyaretçiler, çakmak taşıyla ateş yakma, yün eğirme, eski moda yemekler pişirme, kısa yataklarda dinlenme gibi geçmiş zamanın günlük yaşamının parçaları olan pek çok etkinliği yerine getirebilmektedirler. Günümüzde de ciddiyetin, eğlenmenin, bilgi ve hayalgücünün, huzurun ve dramanın karışımı olarak tüm duyular için duyguların ve düşüncenin çalıştırıldığı bir deneyim ortamı ve hergün bir 'yaşayan müze' yaratılmak istendiği belirtilmektedir (Kron, 2012).

Skansen Avrupa'da özellikle Nordik şehirlerde yeni açıkhava müzeleri açılmasına öncü olmuş; 1897'de Kopenhag'da, 1902'de Oslo'da ve 1909'da Helsinki'de açıkhava müzeleri açılmıştır. (Rentzog, 2007). Daha sonra yogun olarak 1890-1920 ile İkinci Dünya Savaş1 sonrasında 19601970 yılları arasında Avrupa'da kurulmuş; 1920 ve 1930'larda Avrupa dışında da Amerika Birleşik Devletlerinde, Rusya ve Uzak Doğu'da da yaygınlaştırılmışlardır (AEOM, 2007c).

Avrupa'da ilk kurulan çoğu açık hava müzesi, kırsal alanlardaki binalara ve kırsal kültüre odaklanmıştır. 1909'den itibaren ise kent kültürüne odaklanan müzeler de kurulmaya başlanmıştır. 1914'te Danimarka'nın Aarhus'ta kurulan Eski Kent'i (de Gamble by/The Old Town) bunun bir örneğidir (Rentzog, 2007). 1960'lı yıllardan itibaren ise açık hava müzeleri endüstriyel kültüre doğru genişletilmiştir. Örneğin İngiltere'de Ironbridge Gorge Müzeleri Vakfı tarafından yönetilen Ironbridge Gorge Müzeleri bunlardan biridir. 1967'de İngiliz endüstrisinin doğduğu yer olarak belirlenmiş olan ve UNESCO Dünya Mirası Listesi'nde yer alan müze topluluğu, 10 müzeden ve 35 tarihi sit alanından oluşmakta; Endüstri Devrimi'nin kalıntılarını koruma ve yorumlamayı amaçlamaktadır. Ironbridge Gorge'un müze kompleksinin bir parçası olan Blists Hill Victorian Town, 1967'de Endüstri Devrimi'nin kalıntılarını korumak ve yorumlamak için kurulmuştur. Blists Hill, endüstriyel binalardan oluşan bir karışım sunan yeniden inşa edilmiş köy ve Shropshire bölgesindeki diğer yerlerden taşınan binalardan oluşmakta; endüstriyel bir müze olarak sınıflandırılmasına rağmen, dönemin günlük ev yaşamı üzerinde de durmaktadır. On dokuzuncu yüzyıla ait bir 'tipik' Shropshire kasabasını temsil eden müzede geleneksel uygulamalar ve el sanatları, 19. yüzyılın tarihsel yaşamını yorumlayan ve hayat hikayeleri anlatan kostümlü personel tarafindan sergilenmektedir. 
Farklı bir anlayış sergileyen bir başka yaşayan müze, İngiltere'deki Big Pit Ulusal Kömür Müzesi'dir. 1980'de kömür endüstrisindeki düşüşe bağlı olarak kapanana kadar çalışır durumda olan kömür madeni, 1983'te açık hava müzesi/yaşayan müze olarak yeniden açılmıştır (Wales Underground, 2006). Big Pit'i yorumlayan kişiler fiziksel olarak tüm binaları restore ederek sitenin tüm geçmişini tasvir edip geçmişten bir bağlantı oluşturmuştur. Müzenin ana odak noktası eski madencilerin liderliğinde bir yeraltı turudur ve bu tarihten beri Galler için ulusal madencilik müzesi olarak belirlenmiş ve finanse edilmiştir (Thompson, 2005). Diğer pek çok açıkhava müzesi, karakterleri varsayım ve ikincil verilere dayanan kostümlü yorumcular kullanırken Big Pit, tercümanlar ve kılavuzlar için gerçek kömür madencilerini kullanmakta, kişisel deneyimlerinden yola çıkarak ağır endüstrinin gerçekleri hakkında otantik mesaj içeren bir deneyim sunmaktadır.

Avrupa'da pek çok 'arkeolojik açıhava müzesi' de bulunmaktadır. Paardekooper (2012, s.45), arkeolojik açık hava müzelerinde deneyimin ve deneysel arkeolojinin önemini vurgulayarak müzenin ziyaretçileri ile bilim arasında bir köprü oluşturduğunu söyler ve bilimle aktif bir ilişki içinde olan bir müzenin gerçek bir yaşayan müze olduğunu, yaşayan tarih aktörlerinin pekçok arkeolojik açıkhava müzesinin temel ögelerinden biri olduğunu, onların geçmişin gösterimini yaptıklarını belirtir (Paardekooper, 2012, s.62). Paardekooper (2012, s.56) arkeolojik açıkhava müzelerini şöyle sınıflar: Vitrin Müzeleri (alanda veya başka biryerde sergileme/ören yeri müzeleri), arkeolojik veya tarihsel sit alanları, geleneksel/etnografik açık hava müzeleri/tarihi evler, doğal parklar ve kültürel peyzajlar, yeniden yapılandırılmış gemiler, yaşayan tarih müzeleri, hayvan çiftlikleri ve tema parkları.

Yaşayan Tarih Müzeleri (Living History Museum) yaşayan müze kavramı ile en yaygın ilişkilendirilen müze türlerinden biridir. Avrupa ülkelerinde açık hava müzelerinde geçmiş yaşantıları canlandıran, o dönemin giysilerini giymiş aktörler uygulaması Amerika'da daha da geliştirilerek yeni bir müze türünün ortaya çıkmasına yol açmıştır. Bu müzeler 'Yaşayan Tarih Müzeleri' olarak adlandırılmaktadırlar. Magellsen (2007), yaşayan tarih müzelerini 'yeniden inşa edilmiş ya da restore edilmiş alanlarda eğitsel amaçlarla tarihin belli bir döneminin kostümlü olarak yorumlanması' olarak tanılamaktadır. Bu müzelerin ilk örneğini Henry Ford tarafından Dearborn, Michigan'da Greenfield Köyü'nde 1928 y1lında kurulmuştur. 1969'da açılan Kolonyal Williamsburg, müze geliştirme konusunda Kuzey Amerika'da daha büyük bir etkiye sahip olmuş; Mystic Liman, Plimoth Plantation ve Louisbourg Kalesi gibi projeleri etkilemiştir. Çiftlik müzeleri de bu kapsamda oldukça yaygındır (Anderson, 1982). Kuzey Amerikayı Avrupa modelinden ayıran eğilim, yorumlamaya olan yaklaşımı olmuştur. Avrupa'da eğilim genellikle binalar üzerinde yoğunlaşırken, Kuzey Amerika'da birçok açık hava müzesinde dönemin kıyafetlerini giyen ve el işlerini ve gündelik işlerini icra eden tercümanlar olmuştur (Hudson, 1987). Yaşayan tarih müzesi, gerçek insan ve nesnelerle geçtiği mekan içinde tarihi yeniden yaratma pratiği, izleyicilerine tarihi dönemleri yeniden canlandırarak deneysel bir yorumlama olanağı sunan tipte bir müzecilik anlayışıdır. Bu anlayışla bir taraftan koleksiyonun yaşama getirilmesi sağlanırken; diğer taraftan katılımcı yöntemlerle izleyicilerin aktif olarak daha iyi öğrenmeleri sağlanmaktadır. Bu yönüyle yaşayan tarih müzeleri sadece geçmişi temsil etmez, izleyicileri için tarihi gerçekler yaratır; tarihi bir film, konferans veya kitap gibi tarihi üretir (Magelssen, xii, Introduction).

Yaşayan tarih, insanlar tarafından geçmişte, başka zamandaki hayatı canlandırma girişimi olarak tanımlanabilir. Bunun üç temel nedeni Anderson (1982) tarafından şu şekilde açıklanmaktadır: Madde kültürünü daha etkin bir şekilde yaşayan müzede yorumlamak, bir arkeoloji tezini test etmek veya tarihsel etnografiler için veri üretmek ve öğrenme deneyimi olan keyifli bir eğlence etkinliğine 
katılmak. Drama ilk açık hava müzelerinin kuruluşundan başlayarak bu sürecin önemli bir parçası olmuştur ancak yaşayan tarih müzeleri, drama uygulamasının en yaygın kullanıldığı müzelerdir. Yaşayan tarih müzelerinde en yaygın kullanılan drama karakter tipleri birinci kişi rolü ve üçüncü kişi rolüdür. Birinci kişi izleniminde canlandırıcı, tarihi karakterin rolü ve karakterine bürünür. Üçüncü kişi yorumu ile ise dönem rolünün kişiliğini özümsemeksizin, bireylere ilişkin bilgiler verilir ve müze sergilemesi ile ilişkili insanların yaşamları yorumlanır (Ata, 2002; Magelssen, 2007).

Ekomüzeler de tarihi bölgelerin korunmasında ve yenilenmesinde bir teori ve yöntem olarak görülen yaşayan müze kavramı ile bağdaştırılmaktadırlar. 1960'lardan sonra gelişen toplum merkezli yeni müzecilik anlayışının ve kültürel çalışmaların etkileri ile yeni bir müze türü olarak ortaya çıkan ekomüze, bir tür açık hava müzesi ve yaşayan müze olarak değerlendirilmektedir. (Pan, He ve Shi, 2012). Ekomüze kavram1, 1971 y1lında Georges-Henri Rivière ve Hugues de Varine tarafından, Fransa Çevre Bakanlığı ile miras korumasını çevreyle ilişkilendirmek amacıyla ortaya atılmış, Rivière bu terimi on yıl içinde üç kez yeniden tanımlamıştır. 1980'lerdeki tanımı şöyledir: 'Bir kamusal otorite ve yerel bir nüfus tarafindan ortaklaşa tasarlanan, moda edilen ve yönetilen bir alet ... insan ve doğanın bir ifadesi... zaman ifadesi ... uzayın yorumlanmasi ... bir laboratuar ... bir koruma merkezi ... bir okul.

Ekomüze, 'ev' ya da 'yaşam alanı' anlamına gelen Yunan kökü 'oikos' ‘dan gelir. Doğal, sosyal ve kültürel çevrenin bir yansıması olan ekomüze, bir tür açıkhava müzesi olarak değerlendirilmektedir; ancak geleneksel açık hava müzelerinden farklıdır. Ekomüzelerde, müze ziyaretçileri ile kültür ve doğa ait olduğu alanında ve düzeninde paylaşılır. Bu tür açık hava müzelerinin kendilerini ekomüze olarak adlandırmayı tercih etmesinin sebepleri; daha modern ve demokratik olma isteği ve bir müze biçimi olarak farkedilme ihtiyacı olarak açıklamıştır.

Bir ekomüzede, 'miras', 'katılım' ve 'müze' dengeli ve birbirleriyle ilişsi içindedir. Ekomüzelerin temel hedef kitlesi kendi çevrelerinde yaşayan insanlardır. Ekomüzelerde doğa, endüstriyel ve kültürel gelenekler de dâhil olmak üzere belirli bir bölgedeki çeşitli miras çeşitlerinin ve yerel kimliğin korunması, yerel aitlik duygusunu geliştirmesi ve yerel ekonomik gelişme amaçlarını taşımaktadırlar. Yerel nüfusun katılımıyla bu mirasın yönetimi ve işletilmesi gerçekleştirilmekte; etnik gruplara odaklanılmakta ve tüm bölgenin sürdürülebilir gelişmesi için bu gruplar desteklenmektedir.

Pan, He ve Shi (2012, s.99), yaşayan müzenin geleneksel mimari kültürün mekânsal unsurunun orijinalliğinin korunması, geleneksel mimarlık kültürünün kimliği ve mirası, topluluk katılımı ve ziyaretçilerle etkileşim olmak üzere üç özelliğini vurgulamaktadırlar. Yaşayan müze kavramını iki açıdan tanımlamaktadırlar: Müzeler açısından ekomüze, aktif ve ve dinamik bir müze olarak görülmektedir. Ekomüze, koleksiyonları bina duvarlarına sığdırmak yerine kapsam ve içerik olarak genişleme imkanı sunmaktadır. Ekomüze koleksiyonları da yalnızca somut miras değil, aynı zamanda geleneksel geleneklerin aktarılabildiği somut olmayan kültürel mirastır. Sergiler dinamik olarak yerel ortamda korunmakta; zaman ve mekân, statik ve dinamik olarak ustaca biraraya getirilmektedir. Öte yandan, turistlerin ziyaret kalitesini arttırmak için yerel sakinlerin yaşam biçimi ve ritmini özgün bir şekilde korumaya çalışmakta; ziyaretçiler için 'katılım' ve 'deneyim' ortamı oluşturarak daha derin bir anlam taşımaktadırlar. Bölgesel kalkınma modelleri açısından ise tarihi alanların korunması ve yenilenmesi üzerine bir teoridir. Eko müzeler, yerel toplulukların gelişmesinde ve ihtiyaçlarını dile getirmede önemli rol oynar. Ak-Chin Hint topluluğu ekomüze projesinde Nancy Fuller topluluğun güçlendirilmesinde teknikler sağlamıştır (Fuller, 2013). 
Galla da (2005) ekomüzelerin şu özelliklerine dikkat çekmektedir:

- Çevresel eğitim ilkesi olan yerli tarihi, yerel kültürleri, dinsel ve ekolojik çeşitliliği yeniden ortaya çıkarmak, tanımak, saygı göstermek ve bunlardan yararlanmak konusunda oldukça uygun mekanlardır,

- Kamunun kabul gördügü kurumlar ve yerel sakinler tarafından tasarlanırlar. Ortaklaşa sürdürülmeli ve ortak çıkarlar için bir araç olmalıdır,

- Yerel sakinlerin ve ziyaretçilerin kendi çevreleri ile ilgili olarak kendilerini görebilecekleri bir aynadır,

- Doğa ve insanlık arasındaki ilişkinin doğasını göstermektedir,

- Tarih öncesi çağdan günümüze kadar, tarihin uzun dönemlerine karşı yansımayı mümkün kılar,

- Bir süre kalmak isteyen veya sadece ziyaret edenler için ayrıcalıklı alanlar sunar,

- Bir bölgenin geçmiş ve günümüz çevre araştırmalarına katkıda bulunan laboratuvarlardir,

- Doğal kaynakların korunması, konservasyonu ve gelişimi için merkez oluştururlar.

\section{Araștırmanın Amacı}

Müzecilik alanyazınında yaşayan müze kavramının farklı şekillerde kullanıldığ 1 görülmektedir. $\mathrm{Bu}$ durum yaşayan müzenin ne olduğu konusunda anlam karmaşasına neden olabilmektedir. Bu çalışmanın amacı, 'yaşayan müze' kavramının güncel müzecilik çalışmalarındaki kullanımlarını incelemektir. Bu inceleme 'yaşayan müze' kavramı konusunda anlam karmaşasına açıklık getirilmesine ve müzebilim alanındaki terminoloji çalışmalarına katkıda bulunacaktır.

Çalışmanın araştırma sorusu şudur: Güncel müzecilik çalışmalarında ‘yaşayan müze' (living museum) kavramı hangi anlamlarda kullanılmaktadır?

\section{Yöntem}

\section{Araștırma Modeli}

$\mathrm{Bu}$ çalışmada nitel araştırma deseni benimsenmiştir. Araştırma verileri nitel araştırma yöntemlerinden doküman incelemesi yöntemi ile toplanmıştır. Doküman incelemesi, araştırılması hedefenen olgu ya da olgular hakkında bilgi içeren yazılı materyallerin analizini kapsamaktadır (Yıldırım ve Şimşek, 2006, s.187). Çalışmada ulusal ve uluslararası ortamda 'yaşayan müze' kavramına olan müzecilik yaklaşımları ve uygulama örneklerini incelemek için betimsel tarama yöntemi çerçevesinde ilgili alanyazına yoğunlaşılarak çözümleme yapılmıştır.

\section{Örneklem}

Çalışmada müzebilimalanındakialanyazın evrenindeörneklemolarak ICOM'un(International Council of Museums/Uluslararası Müzeler Konseyi) yayınladığ 'Museum International' dergisi seçilmiştir. 1948'de ICOM'un UNESCO ile birlikte 'Museum' adıyla çıkarmaya başladığı, daha sonra 'Museum International' adıyla ICOM'un devam ettiği Art and Humanities Citation Index'te yer alan bu yayın, uluslararası müzecilik alanında en güvenilir bilimsel bilgilerin paylaşıldığı ve 
müzeciliğe bakış konusunda en güncel kavramlar ile uygulamalarının paylaşıldığı dergi olması nedeni ile belirlenmiştir.

\section{Verilerin Toplanması ve Analizi}

Çalışmada Museum International'ın Yıldız Teknik Üniversitesi kütüphanesinin elektronik kaynaklarında bulunan 2000-2016 yılları arasındaki sayıları 'living museum' anahtar kelimesi ile taranmıştır. Tarama sonucunda içinde 'yaşayan müze' kavramı geçen ve bu kavramı 'müze' kurumu ile ilişkili olarak kullanan makaleler tespit edilmiş; her makalede 'yaşayan müze' kavramının nasıl ele alındığı tek tek incelenmiştir. Daha sonra alayazınla ilişki içinde tüm makalelerle ilişkili olarak toplu bir değerlendirme yapılmıştır.

\section{Bulgular ve Yorum}

Yapılan tarama sonucunda, 'yaşayan müze' kavramının bulunduğu yedi makale incelenmiştir. Öncelikle, bu makalelerde yaşayan müze kavramının ele alınışı 2000'li yıllardan başlayarak tarih sırasıyla ayrı ayrı incelendikten sonra genel bir değerlendirme yapılmıştır:

- Museum International'in 205. sayısinda (Vol. 52, No. 1, 2000) Greg Van Alstyne'nin 'www.moma.org'da Sibernetik, Modernizm ve Zevk/Cybernetics, Modernism and Pleasure in www.moma.org' adlı makalesinde New York Modern Sanat Müzesi/ MOMA’nın web sitesinin mantı̆̆ını incelenmektedir. Yazıda öncelikle MOMA'nın tasarım ilkelerinden söz edilmekte ve bu ilkelere göre web sitesi tasarımını nasıl gerçekleştirdikleri konusunda yaşadıkları zorluklar arasında, yaşayan müzedeki gelgit ve enerji akışını web sitesinin büyümesi ve gelişmesi için nasıl teşvik ettiği meselesini nasıl çözdüklerini açıklamaktadır. Burada 'yaşayan müze'den kastedilen MOMA'nın fiziksel sergilemesidir. Yani burada yaşayan müze, iletişimsel açıdan ele alınmış, müze web sitesinin yanında müze ortamındaki canlılık ve hareketlilik 'yaşayan müze' olarak nitelenmiştir.

- Museum International'nn 213-214. sayıs1 (Vol. 54, No. 1 \& 2, 2002) Angkor sit alan1 özel sayısı olarak yayımlanmıştır. O dönemde UNESCO'nun tehlike altındaki kültürel miras listesinde yer alan ve günümüzde UNESCO Kültürel Miras listesinde bulunan Angkor, bir arkeolojik açık hava müzesidir. Bu sayının editör yazısında Koïchiro Matsuura, Angkor'un gerçekten bir 'yaşayan müze' olduğunu belirtmekte; bu kavram için yeterli gerekçe sağladığını söylemektedir. Daha iyi bir gelecek inşa etmek için geçmişe verilen önemle, Angkor sit alanının bize miras hakkında derin bir anlam kazandırdığı, yaşayan bir müze olarak onu yaratan, koruyan ve varlığını devam ettiren insanlığın kaderine açık olduğu belirtilmektedir. Burada Angkor için 'yaşayan müze', arkeolojik açık hava müzesi bağlamında kullanılmaktadır.

- 227. sayıda (Vol. 57, No. 3, 2005) Amareswar Galla, 'Vietnam'da Ekomüzede Kültürel Çeşitlilik Gelişimi/ Cultural Diversity in Ecomuseum Development in Viet Nam' başlıklı yazısında, yerel topluluk paydaş grupları tarafından gerçekleştirilen, Ha Long koyunun ekomüzeye dönüştürülme projesini açıklamaktadır. Makalede ekomüze aracılığıyla yerel olarak kendini güçlendirme süreci ile doğal ve kültürel miras ayırımı olmadan kültürel miras değerlerinin bütüncül bir anlayışla ele alındığı 
ifade edilmekte; ekomüze konsepti ile Ha Long koyunun tamamı bir 'yaşayan müze' olarak görülmektedir. Ekomüze projesi ile tüm insan ve doğal ekosistem çevresinde yaşayan ve gelişen organizmalar olduğu; insan ve doğal ekosistemin birbirinden bağımsız olarak soyutlanmış bir alanda korunamayacağı ileri sürülmekte; Ha Long Koyun'da sürdürülebilir gelişmesi nihai hedefi ile yorumlayıcı bir yaklaşım uygulandığ 1 belirtilmektedir. Burada 'yaşayan müze', hem nesne olarak tanımlanan somut ve somut olmayan kültürel miras, hem de yorumlayıcı etkinlikleriyle ekomüze kavramı çerçevesinde kullanılmaktadır.

- 233-234 sayısının konusu (Vol. 59, No. 1/2, 2007) 'Göçmenlerin Kültürel Miras1/ The Cultural Heritage of Migrants'dır. Bu sayının editorü Isabelle Vinson yazısında Fransa'daki Cite' Nationale de l'histoire de l'immigration/Ulusal Göç Tarihi Sitesi'nin hem teması hem de koruma yaklaşımıyla sadece bir müze değil, kültürel etkinlikler, bir kaynak merkezi, bir eğitim projesi ve ortak bir ağ içeren bir ulusal merkez olduğunu ifade etmektedir. Müzenin, kültürel etkinlikleri programlayacağı; temanın farklı yönleri ile ilgili seçimlere dayalı sürekli sergiler sunacağı; çeşitli geçici sergiler aracılığıyla sadece göç sorunu ile sınırlı olmayıp günümüz toplumlarının ve genel olarak dünyanın karşı karşıya bulunduğu birçok meseleyi de benimseyeceği ifade edilmektedir. Sergilerin yanında çağdaş dünyamızı sorgulamaya ve bu konulara duyarlı bir yaklaşım önermeye çalışarak sanatçı rezidansları, küçük ölçekli müze binası dışı gösterimler, gezici etkinlikler ve atölye çalışmaları ile 'yaşayan müze' yaklaş1mında olacağ 1 belirtilmektedir. Burada 'yaşayan müze', müze dışında sergilemeler ve bu etkinliklere ek olarak müze binası dışında sunulacak iletişim çalışmaları ile ilişkili olarak ele alınmaktadır.

- $\quad$ 237-238 (Vol. 60, No. 1-2, 2008) sayılı dergide, Pan Shouyong'un 'Müzeler ve Somut Olmayan Kültürel Mirasin Korunmasi/Museums and the Protection of Cultural Intangible Heritage' adlı makalesinde, Çin>in somut olmayan kültürel mirasını müzelerde canlı tutmanın yollarının ele alınması gerektiği belirtilmektedir. Bunun yolları olarak da yerli bölgelerdeki her türlü somut olmayan mirasın dijital ortama aktarılabilmesi için sanal müzelerin kullanılması ve erişilebilir formatlarda halka açık hale getirilmesi; somut ve somut olmayan mirasın korunması için 22 ekomüze kurulmasının tartışılması; ayrıca yaşayan müze programlarının bir parçası olarak ulusal azınlık müzelerinin popüler halk sanatçılarının kullanımı için halka açık meydanlar ve dış mekânlar sağlaması gerektiğini belirtmektedir. Bu makalede yine 'yaşayan müze', halk kültürünün sergilendiği ve popüler halk sanatçılarının dış meknda performanslar yaptığı açıkhava müzeleri ile bağdaştırılmaktadır.

- 247 sayılı dergide (Vol. 62, No. 3, 2010), Joe“1le Rostkowski tarafindan yazılan ’Ötekilerin Sanatının Sunumu ve Yorumu: Amerika Yerlileri İncelemesi/Presentation and Interpretation of the Art of Others: the Case of Amerindians' başlıklı yazısında, etrafindaki resmi anıtların mimarisinin yanında Ulusal Amerika Yerlileri Müzes/National Museum of American Indian'ın müze binasının kolayca farkediliyor olması, bahçesinin bir etnobotanist tarafından tasarlanması, bahçesinde Yeni Dünya'nın tütün, mısır, kabak vb. bitkilerinin olması, Amerikan çöl ve orman havasını hissettirmesi, kıtada 
uzun süredir varlığını sürdüren yerlileri simgeleyen 'büyükbaba' olarak bilinen taş blokların olması ile müze mimarisinin etkinliklerle hayata geçirilmesi vurgulanmakta ve dönemin müdürü Richard West tarafından 'farklı bir yaşayan müze' olarak görüldügü belirtilmektedir. Burada müzenin ait olduğu coğrafyaya özgü çevresel düzenlemelerle bir nevi yaşayan müze olduğu benzetmesi yapılmakta, botanik bahçeleri ile ilişki kurulmaktadır. Ko'nun (2011) 'yaşayan müze' sınıflamasına göre bu bahçe botanik bahçesi niteliğinde olması nedeni ile yaşayan müze olarak değerlendirilebilir. Burada yaşayan nesne koleksiyonuna sahip olması nedeni ile bu niteleme yapılmıştır.

- 1971-1977 yılları arasında ICOM başkanlığını yürüten Jan Jelinek'in 1975 yılı’nda Museum International'ın 28. sayısında yayınlanan Modern, Yaşayan Müze/The Modern, Living Museum başlıklı makalesi, 2014 yılında 261-264. sayıda tekrar yayınlanmıştır. Müzenin genel olarak eğitim potansiyelinin tartışıldığı makalede, müzenin sadece nesneleri bir sergiyle sunan değil, nesnelerin karekterini, işlevini ve kullanımını açıklayan ve izleyicilerine kişisel katılım olanakları sunan bir müze olması gerektiği vurgulanmaktadır. Bu görüşle alakalı olarak, bir sergi sistemi olarak temalı sergilerin yoğun bir şekilde örgütlenmesinin yanı sıra gençler ile birlikte çalışmanın ve ekolojik, sosyolojik ve çevresel konuları vurgulamanın modern, yaşayan müzenin karakteristik bir özelliği olması gerektiği vurgulanmaktadır. Burada çevresel konuların ele alınıyor olması nedeniyle 'yaşayan müze' kavramıyla ekomüzelerle bağdaştırma yapilmaktadir.

Genel olarak bu çalışmaların yaşayan müze kavramını ele alış biçimlerini değerlendirdiğimizde yaşayan müze kavramına olan yaklaşımların 'müze türleri ile ilgili olan' ve 'müze iletişim yöntemleri ile ilgili olan' olarak iki temel gruba ayrılabileceği sonucuna varılmıştır.

Çalışmada incelenen makalelerden üç tanesinde (\%43, Matsuura 2002; Galla, 2005; Rostkowski, 2010) 'yaşayan müze' kavramı, müzelerin 'hizmet ettikleri alan' ve 'koleksiyonlarını sergileme biçimleri’ temel alınarak sınıflama yapılan müze türleri ile ilişkili olarak ele alınmaktadır. Aslında bu müzelerin her biri 'yaşayan müze' türlerinden biridir. Bir makalede 'arkeolojik açık hava müzesi', bir makalede 'eko müze', bir makalede ise 'botanik bahçesi' ile ilişkili olarak yaşayan müze kavramına yer verilmiştir. Bu müzelerde ziyaretçi iletişimi için öncelikle müzenin ait olduğu coğrafya, fiziksel yerleşimi ile yaşayan kültür örneklerinin de bulunduğu somut kültürel mirası bulunmaktadır. Daha geniş bağlamda ise izleyicinin de katılımının sağlandığ 1 çeşitli drama tekniklerinin kullanıldığı, performanslarla ve yorumlayıcı etkinliklerle somut olmayan kültürel mirasın paylaşımı ve yaşam biçimlerinin canlandırılması yapılmaktadır.

Diğer dört makalede ise (\%57, Alstyne, 2000; Vinson 2007, Shouyong, 2008; Jelinek, 2014) müzenin fiziksel ortamındaki canlılık ve hareketlilikle ve ziyaretçileriyle geliştirdikleri iletişim yöntemleri nedeniyle 'yaşayan müze' kavramı ile ilişki kurulmuştur. Bu kavram, müze iletişimi yöntemleri açışından ve 'nesne merkezli' ya da 'durağan müze' kavramının karşıtı olarak; etkinliklerini ‘etkileşim', 'katılım', 'yorum' ve 'kapsayıcılık' gibi kavramlarla ilişkili ve aktif izleyici anlayışı ile biçimlendiren müzeler için kullanılmakta, bu müzelerin yaşayan müze gibi olacağ1 benzetmesi yapılmaktadır. Yani bu müzelerin kendileri 'yaşayan müze' türlerinden biri değildir ancak 'yaşayan müze'nin izleyici yorumlarına ve katılımına açı olan yönleri nedeniyle (MOMA dışında) bu müzeler için 'yaşayan müze' benzetmesi yapılmaktadır. Alstyne (2000), New York Modern Sanat Müzesi/MOMA'nın fiziksel ortamındaki canlılık ve hareketliliği 'yaşayan müze' olarak nitelemiştir. 
Vinson (2007), Fransa' daki göç müzesinde, yaşam biçimlerinin gösteriminin önemine değinmiş; bu anlamda müzenin 'yaşayan müze' yaklaşımında olacağını belirterek, çeşitli performans gösterileri yapan ve belli bir hareketin olduğu izleyici merkezli yaklaşıma gönderme yapmıştır. Shouyong (2008) Çin'in somut olmayan kültürel mirasını müzelerde canlı tutmanın yollarından biri olarak azınlık müzelerinde popüler halk sanatçıların kullanımı için halka açık meydanlar ve dış mekânlar sağlanması gerektiğini; bunların 'yaşayan müze' programlarının bir parçası olduğunu belirtmekte; burada yine dış mekânda kültürün sergilenmesi ve yorumu ile ilişkili olarak 'yaşayan müzenin' açık havada performans etkinlikleriyle ilişki kurmaktadır. Jelinek (2014) çalışmasında izleyici merkezli müzecilik anlayışına gönderme yaparak nesneleri sergilemenin yanında izleyicilerine, nesnelerin karekterini, işlevini ve kullanımını açıklayan, kişisel katılım olanakları sunan ve ekolojik, sosyolojik ve çevresel konuları vurgulayan müzenin modern, yaşayan müze olduğunu belirtmektedir.

\section{Sonuç ve Öneriler}

Müzecilik terminolojisinde farklı kullanımları olan kavramlardan biri de 'yaşayan müze'dir. Genellikle açık hava müzesi ile eş anlamlı kullanılan ‘yaşayan müze', halk mirası veya yöresel kültürel miras ile ilişkilendirilen koleksiyonlarını dış mekânda sergileyen, toplumsal tarihi ve geleneksel yaşam biçimlerini temsil etmeyi amaçlayan müzelerdir. 'Yaşayan müze' kavramı Skansen Açık Hava Müzesi ile başlayarak halk müzeleri, çiftlik müzeleri, yaşayan tarih müzeleri, ekomüzeler, botanik bahçeleri gibi farklı müze türleri için de kullanılmıştır.

Henüz müzecilikte nesne merkezli anlayışın hakim olduğu dönemlerde açık hava müzeleri ile etkinlik göstermeye başlayan 'yaşayan müzeler', izleyicileri ile iletişim kurmuşlar; Ambrose ve Paine'in de vurguladığı gibi (2012) koleksiyonlarını canlandırmak ve ne anlama geldiğini toplumla paylaşmak için gösterimler ve drama yöntemlerini kullanmışlardır. Açık hava müzelerinden ekomüzelere müzecilik tarihi içinde gelişen pek çok 'yaşayan müze' türünde bu yöntemleri kullanmışlar ve de kullanmaya devam etmektedirler. Yaşayan müzelerin en belirleyici özelliklerinden biri, izleyicilerin kültürel miras ile çeşitli miras etkinlikleriyle etkileşime girmesini sağlayacak veya kendi hikayesini anlatacak karakterleri kullanması ve böylece pasif izleyici' yerine 'aktif izleyici' olmalarını sağlamasıdır.

Bu çalışmada, yaşayan müze' kavramının güncel müzecilik çalışmalarındaki kullanımlarını incelemek amaçlanmıştır. Bunun için, doküman incelemesi yöntemiyle, ICOM'un yayınladığı müzecilik alanında AHCI'e girmiş en güncel kavram ve uygulamaların tartışıldığı 'Museum International' örneklem olarak ele alınmıştır. 2000'li y1llardan başlayarak 'living museum' anahtar kelimesi ile gerçekleştirilen taramada, içinde 'yaşayan müze' kavramı geçen 7 makale tespit edilmiştir. Bu makaleler, 'güncel müzecilik çalışmalarında 'yaşayan müze/living museum' kavramı hangi anlamlarda kullanılmaktadır?’ araştırma sorusu bağlamında incelenmiştir.

Yapılan inceleme sonucunda, yaşayan müze kavramına olan yaklaşımların 'müze türleri ile ilgili olan' ve 'müze iletişim yöntemleri ile ilgili olan' olarak iki temel gruba ayrılabileceği sonucuna varılmıştır. Çalışmada incelenen makalelerden üç tanesi (Matsuura 2002; Galla, 2005; Rostkowski, 2010) 'yaşayan müze' türüdür. Müzelerin 'hizmet ettikleri alan' ve 'koleksiyonlarını sergileme biçimleri' temel alınarak sınıflaması yapılan müze türleridir; bir makalede 'arkeolojik açık hava müzesi', bir makalede 'eko müze', bir makalede ise 'botanik bahçesi' 'ile ilişkili olarak ele alınmışlardır. Diğer dört makalede ise (Alstyne, 2000; Vinson 2007, Shouyong, 2008; Jelinek, 2014) 
müze iletişimi yöntemleri açışından ve 'nesne merkezli' ya da 'durağan müze' kavramının karşıtı olarak, etkinliklerini 'etkileşim', 'katılım', 'yorum', 'kapsayıcılık' vb. kavramlarla ilişkili aktif izleyici anlayışı ile biçimlendiren müzeler için kullanılmaktadır. Bu müzelerin yaşayan müze gibi olacağı benzetmesi yapılmaktadır. Makalelerin yarısından fazlasında, müzenin fiziksel ortamındaki canlılık ve hareketlilikle ve ziyaretçileriyle geliştirdikleri kişilerarası iletişim yöntemleri nedeniyle 'yaşayan müze' kavramı ile ilişki kurulmuştur.

Toplum merkezli müzecilik anlayışının yerleşmesi sonrasında müzelerde iletişim çalışmalarının önem kazanması ile yaşayan müzelerde kullanılan iletişim ve yorum çalışmaları diğer tüm müze türlerinde de görülmeye başlamıştır. Özellikle 1990'lardan itibaren müzelerde eğitim bölümlerinin yaygınlaşmaya başlaması ve farklı izleyici gruplarına yönelik etkileşimli atölye çalışmaları, drama uygulamaları vb. çalışmaların da yaygınlaşmasını sağlamış; 2000'li yıllardan sonra ise 'insan ve toplum merkezli anlayış’ tüm müzeler için temel bir gereklilik olmuştur. Müzelerin izleyicileri ile iletişiminde kişilerarası iletişim; kişisel seçim, bireysel öğrenme deneyimi ve bütün içinde seçilmiş ilgiler önem kazanmıştır. Artık bireylerin özel ihtiyaçlarına göre gruplara ayrılması ve onların ilgi, ihtiyaçlarına göre kişilerarası iletişim yöntemlerinin kullanılması gerektiği anlaşılmış; pasif izleyici kavramı, aktif izleyici ile yer değiştirmiş̧ir. Aktif izleyici kavramının gelişimi ile kitle iletişismin yerini kişilerarası iletişim almıştır (Hooper-Greenhill, 1994). Günümüzdeki anlamı ile müzeler, toplumun eğitsel ve kültürel gelişimine hizmet etmek için somut ve somut olmayan nesneleri toplamakta ve sergilemektedirler; bu nedenle izleyicilerin müzede aktif vakit geçirmeleri için gerek sergi teknolojileri, gerekse etkinlikleriyle farklı seçenekler sunmaktadırlar. Özellikle teknolojinin getirdiği olanaklarla da pek çok yeni yöntem kullanılmaya başlanmıştır. Kiosklarla başlayan müzecilik teknolojileri, müzelerde i-pad ve akıllı telefon uygulamalarının başlaması ile daha da gelişmiş̧ir. Örneğin sergi salonlarında nesnelerin nasıl kullanıldığını gösteren filmler, belli mesleklerin nasıl icra edildiği o mesleğe ait nesnelerin yanında mesleğin ustaları tarafından icra ediliş sürecini gösteren filmlerle birlikte sergilenmektedir. Çeşitli teknolojiler kullanılarak izleyici etkileşimine olanak sağlayan sergileme elemanları sergi salonlarında yerini almaktadır. En iyi uygulamalardan biri de augmented reality (artırılmış gerçeklik) tekniğiyle hazırlanan animasyonların iPad'ler ve akıllı telefonlar aracılığıyla izlenebildiği uygulamalardır. Müzelerde teknolojinin olanakları ile facebook, tweeter vb. sosyal medya araçları kullanılarak da izleyicilerle uzaktan da iletişimi kurulmakta ve çeşitli etkinlikler geliştirilmektedir.

Sonuç olarak günümüzde müzelerin çeşitli iletişim yöntemlerini kullanarak, izleyicileriyle müze içi ve dışında temasta oldukça canlı ve hareketli mekânlar olmaları gerekmektedir. Bu özellikler artık sadece yaşayan müzelerde değil, pek çok müze türünde görülmektedir. Bu nedenle yukarıda tespit edilen ikinci grupta olduğu gibi müzelerin fiziksel ortamındaki canlılık ve hareketlilikle ve ziyaretçileriyle geliştirdikleri iletişim yöntemleri nedeniyle '(yaşayan müze' yaklaşımında olmaları ya da 'yaşayan müze' programları düzenlemeleri) günümüzde hâlâ 'yaşayan müze' benzetmesi ile kullanılması yerine müzecilik çalışmalarında ortaya çıkan 'kapsayıcı', 'etkileşimli', 'izleyici merkezli' vb. pek çok yeni kavramla ilişkili olarak kullanılabileceği düşünülmektedir. 'Yaşayan müze' kavramı ise 'koleksiyonlarını dış mekânda sergileyen, toplumsal tarihi ve geleneksel yaşam biçimlerini ya da doğal ve kültürel miras ile somut ve somut olmayan mirası temsil etmeyi amaçlayan 'halk müzeleri', 'açıkhava müzeleri', ‘ekomüzeler' vb. için kullanılabilir. 


\section{Kaynakça}

AEOM (2017a). Definition, Retrieved February 2017, from http://aeom.eu/en/?page_id=95,\%20AEOM

AEOM (2017b). Open-Air Museums, Retrieved February 2017, from http://aeom.eu/en/?page id=58

AEOM (2007c). History, Retrieved February 2017, from http://aeom.eu/en/?page_id=100

Alstyne, G.V. (2000). Cybernetics, modernism and pleasure in www.moma.org. Museum International, 52, (1), 35-41.

Ambrose, T. ve Pain, C. (2012). Museum basics. Third edit. London, New York: Routledge.

Anderson, J. (1982). Living History: Simulating everyday life in living museums. American Quarterly, 34(3), 290-306. Retrieved June 2017, from http://www.jstor.org/stable/2712780

Ata, B. (2002). Müzelerle ve tarihi mekanlarla tarih öğretimi: tarih öğretmenlerinin müze eğitimine ilişkin görüşleri. Yayınlanmamış doktora tezi. Gazi Üniversitesi Sosyal Bilimler Enstitüsü Tarih Eğitimi Anabilim Dali, Ankara.

Burke, P. (1996). Yeniçağ bașında Avrupa halk kültürü. Ankara: İmge Yay., 1996.

Demir, S. (2013). Türkiye'de açık hava müzeleri açıldı açılıyor: açık hava müzelerine yeni bir bakış. Milli Folklor, 25 (99), 145-158.

Dürrschmidt, K. (2012). Living museums as a way of preserving cultural knowledge, ICME-ICOM Annual Meeting Commodifying Culture? Cultural Villages and Living Museums (Abstract Book) Namibia: ICME-ICOM.

Fuller, N. (2013). The museum as a vehicle for community empowerment: the Ak-Chin Indian community ecomuseum project, Museums and communities: the politics of public culture (edit. Ivan Karp, Christine Mullen Kreamer,Steven Levine). London, Washington: Smithsonian Institution, 327-365.

Galla, A. (2005). Cultural diversity in ecomuseum development in Viet Nam. Museum International. 57 (3), 101-109.

Galangau-Quérat, F. ve Girault, Y. (2012). The museum's experience in Cameroon as a media for tangible and intangible heritage. ICME-ICOM Annual Meeting Commodifying Culture? Cultural Villages and Living Museums (Abstract Book) Namibia: ICME-ICOM.

Hooper-Greenhill, E. (1994). Museums and their visitors. London, New York : Routledge.

Hudson, K. (1987). Museums of influence, Cambridge University Press.

Hudson, K. (1998). Museum refuses to stand still, Museum International, 50 (1), 43-50.

Ironbridge Gorge Trust. (2017) Ironbridge Gorge Museums, Retrieved March 2017, from https://www.ironbridge.org.uk/explore/museum-of-the-gorge/

Jelinek, J. (2014). The modern, living museum. Museum International. 66 ( 1-4), 58-61.

Ko, J.L. (2011), Cultural Representations and Museums: The Construction of Ethnic Identity in Chicago's Chinatown, The University of Wisconsin - Milwaukee, ProQuest Dissertations Publishing, Milwaukee.

Kron, E. (2012). The story of a model designing culturally historic environment using a modern narrative, Open Air Museums Memoir, Sirogojino: The Open Air Museum Old Village in Sirogojno.

Letsebe, O.V. (2012). The Living Museum and Cultural Villages: Revival of Traditional Cultures in Botswana, ICME-ICOM Annual Meeting Commodifying Culture? Cultural Villages and Living Museums (Abstract Book) Namibia: ICME-ICOM.

Madran, B.(?) Müze Türleri. Yeniden Müzeciliği Düşünmek. (Ed., Tomur Atagök). İstanbul: Yıldız Teknik Üniversitesi Matbaas1, 3-10.

Magelssen, S. (2007). Living history museums: Undoing history through performance. Maryland: Scarecrow press.

Matsuura, K. (2002). Preface. Museum International: Angkor: a living museum. 54 (1-2). 6-8.

Y. Pan, L. L. He, Y. Shi. (2012). Practice of 'Living Museum' in the Traditional Architecture Culture Protection 
and Renewal in South Fujian, Applied Mechanics and Materials Online. 209-211, 98-102 doi:10.4028/ www.scientific.net/AMM.209-211.98

Paardekooper, R. (2012). The value of an archaeological open-air museum is in its use. Leiden: Sidestone Press. Retrieved July, from https://tr.scribd.com/document/119270251/Paardekooper-2012-The-Value-of-an-Archaeological-Open-Air-Museum-is-in-Its-Use

Rentzog, S. (2007). Open air museums the history and future of a visionary idea, ALFHAM and Association of European Open Air Museums.

Rostkowski, J. (2010). Presentation and interpretation of the art of others: the case of amerindians'. Museum International, 62 (3), 31-40.

Shouyong, P. (2008). The protection of cultural intangible heritage, Museum International, 60 (1-2), 12-19.

Sukmataji, (2010). A Study on Sustainable Tourism Development in Batavia, Jakarta, Indonesia, living museum proceedings, Proceedings of Regional Conference on Tourism Research The State of the Art and its Sustainability.

Tezcan Akmehmet, K ve Ödekan, A. (2006). Müze eğitiminin tarihsel gelişimi, itüdergisi/b Sosyal Bilimler, :3 (1), 47-58.

UNESCO, 2003. Somut Olmayan Kültürel Mirasın Korunması Sözleşmesi, Retrived October 2006, from https://ich.unesco.org/doc/src/00009-TR-PDF.pdf

Vinson, I. (2007). Editorial: the legacy of migrants. Museum International. 59(1-2), 4-7.

Yıldırım, A. ve Şimşek, H. (2007). Sosyal bilimlerde nitel araştırma yöntemleri (6. Bask1). Ankara: Seçkin Yay. Wilks, C. ve Kelly, C. (2008). Fact, Fiction and Nostalgia: An Assessment of Heritage Interpretation at Living Museums, International Journal of Intangible Heritage, 3, 128-140. 
